\title{
GMR
}

\section{Random regression analysis of test-day milk yields in the first and second lactations of Brazilian Gyr cows}

L.G. Gonzalez-Herrera ${ }^{1,2}$, L. EI Faro ${ }^{3}$, A.B. Bignardi ${ }^{4}$, R.J. Pereira ${ }^{4}$, C.H.C. Machado ${ }^{5}$ and L.G. Albuquerque ${ }^{1,6}$

1'Departamento de Zootecnia, Faculdade de Ciências Agrárias e Veterinárias, Universidade Estadual Paulista, Jaboticabal, SP, Brasil

${ }^{2}$ Grupo de Investigación en Biodiversidad y Genética Molecular, Universidad Nacional de Colombia, Facultad de Ciencias Agrarias, Medellín, Colombia

${ }^{3}$ Centro de Pesquisas de Bovinos de Corte, Instituto de Zootecnia,

Sertãozinho, SP, Brasil

${ }^{4}$ Grupo de Melhoramento Animal de Mato Grosso,

Instituto de Ciências Agrárias e Tecnológicas, Universidade Federal de Mato Grosso, Campus Universitário de Rondonópolis, Rondonópolis, MT, Brasil

${ }^{5}$ Associação Brasileira dos Criadores de Zebu,

Superintendente Técnico-Adjunto de Melhoramento Genético, Uberaba, MG, Brasil ${ }^{6}$ Conselho Nacional de Desenvolvimento Científico e Tecnologico,

Instituto Nacional de Ciência e Tecnologia - Ciência Animal, Brasília, DF, Brasil

Corresponding author: L.G. de Albuquerque

E-mail: Igalb@fcav.unesp.br

Genet. Mol. Res. 14 (4): 16497-16507 (2015)

Received May 22, 2015

Accepted August 25, 2015

Published December 9, 2015

DOI http://dx.doi.org/10.4238/2015.December.9.22

ABSTRACT. The objective of the present study was to estimate the genetic parameters for test-day milk yields (TDMY) in the first and second lactations using random regression models (RRM) in order to contribute to the application of these models in genetic evaluation of milk yield in Gyr cattle. A total of 53,328 TDMY records from 7118 lactations of $5853 \mathrm{Gyr}$ 
cows were analyzed. The model included the direct additive, permanent environmental, and residual random effects. In addition, contemporary group and linear and quadratic effects of the age of cows at calving were included as fixed effects. A random regression model fitting fourth-order Legendre polynomials for additive genetic and permanent environmental effects, with five classes of residual variance, was applied. In the first lactation, the heritabilities increased from early lactation (0.26) until TDMY3 (0.38), followed by a decrease until the end of lactation. In the second lactation, the estimates increased from the first $(0.29)$ to the fifth test day (0.36), with a slight decrease thereafter, and again increased on the last two test days $(0.34$ and 0.41$)$. There were positive and high genetic correlations estimated between first-lactation TDMY and the remaining TDMY of the two lactations. The moderate heritability estimates, as well as the high genetic correlations between half the first-lactation TDMY and all TDMY of the two lactations, suggest that the selection based only on first lactation TDMY is the best selection strategy to increase milk production across first and second lactations of Gyr cows.

Key words: Covariance functions; Dairy cattle; Genetic evaluation; Legendre polynomial

\section{INTRODUCTION}

Random regression models (RRM) have been proposed as the most adequate models to describe changes in the (co)variances of repeated measures obtained throughout the life of an animal, such as milk yield, which is measured monthly (Jamrozik and Schaeffer, 1997). These models assume all production records of the same animal to be the same trait (Kirkpatrick et al., 1994), but consider environmental differences between measures, an approach that permits estimation of the trajectory of the trait over time for each animal as a deviation of the fixed curve estimated for the population. In general, orthogonal Legendre polynomials have been employed in RRM to model the random trajectories for additive and permanent environmental effects, as well as the fixed trajectory, which have shown better convergence properties than models using other functions (Pool et al., 2000; Schaeffer, 2008).

Several studies have demonstrated the existence of a genetic correlation between testday milk yields of the same lactation and between test-day yields of different lactations (Guo et al., 2002; Yang et al., 2005; Cobuci et al., 2011). However, preliminary studies have shown differences in the lactation curve between the first and second lactation, and between the second and subsequent lactations. In some countries such as Germany, the Netherlands, and the United States, multitrait random regression analysis including the first three lactations has been used for the genetic evaluation of dairy cattle.

The dairy Gyr (Bos indicus) breed is present in more than $80 \%$ of Brazilian dairy herds as purebreds or as crossbreeds with Holstein cattle (Reis Filho, 2006). It is important that breeding values for milk yield of different lactations are available. However, the breeding program of this breed has focused mainly on first-lactation milk yield. The objective of the present study was to estimate genetic parameters for test-day milk yields in the first and second lactations using RRM in order to contribute to the application of these models in genetic evaluations of milk yield in the Gyr cattle. 


\section{MATERIAL AND METHODS}

Test-day milk yields (TDMY) of first and second lactations of Gyr (Bos indicus) cows were analyzed using bivariate RRM. The data were obtained from the Brazilian Association of Zebu Breeders (Associação Brasileira de Criadores de Zebu - ABCZ).

The test-day records were obtained starting on the fifth day after calving and were truncated at 305 days of lactation, with the first record being obtained up to 45 days after calving. The mean age at first and second calving was 40.4 and 57.42 months, respectively. Test-day milk yields were divided into monthly classes of days in milk, ranging from one to 10 classes. Contemporary groups were formed by herd-year-season of test day (one corresponding to the rainy season (October to March) and the other to the dry season). Only data of animals with at least three animal-observations were kept. Additionally, records exceeding 3.5 standard deviations above or below the overall mean for the contemporary group were eliminated.

A total of 53,328 TDMY records from 7,118 lactations of 5,853 Gyr cows were analyzed. The cows had calved between 1983 and 2009 and belonged to 238 herds in Brazil. The relationship matrix contained 15,209 animals. The structure of the dataset after editing is summarized in Table 1.

Table 1. Number of sires and dams with female offspring with test-day milk yield (TDMY) records, number of contemporary groups, and mean lactation length of the first and second lactation of Gyr cows.

\begin{tabular}{lcc}
\hline Information & Lactation 1 & Lactation 2 \\
\hline Sires with female offspring with production records & 731 & 338 \\
Dams with female offspring with production records & 3,725 & 1,242 \\
Females with production records & 5,534 & 1,584 \\
Number of females in the pedigree & 1,827 & 1,100 \\
Number of sires in the pedigree & 7,010 & 2,939 \\
TDMY & 41,338 & 11,990 \\
Lactation length (days) & 292.7 & 285.6 \\
Contemporary group & 1,452 & 541 \\
\hline
\end{tabular}

Analysis was performed using a bivariate RRM by Bayesian inference on orthogonal Legendre polynomial. The model included the direct additive, permanent environmental and residual random effects. In addition, contemporary group and linear and quadratic effects of the age of cow at calving were included as fixed effects. The average lactation curve of the population was modeled with a fourth-order orthogonal Legendre polynomial. Legendre polynomials were used to fit genetic additive and permanent environmental random effects.

The choice of the order of covariance functions to describe the random effects was based on the results of Pereira et al. (2013) who applied RRM to describe first-lactation TDMY in Gyr cattle employing part of the database used in this study. After comparing the different models based on total residual variance criteria, the percentage of reduction in model complexity (Bozdogan, 2000), and the Akaike and Schwarz Bayesian information criteria (Wolfinger, 1993), the authors indicated a random regression model fitting fourth-order Legendre polynomials for additive genetic and permanent environmental effects, with 5 classes of residual variance.

The matrix presentation of the RRM is given by:

$$
y=X b+Z a+W p+e
$$

where $y$ is the vector of observations; $b$ is the vector of systematic effects and fixed regression coefficients; $a$ is the vector of additive genetic random regression coefficients; $p$ is the vector of 
permanent environmental random regression coefficients; $e$ is the vector of the random residual effect, and $X, Z$, and $W$ are incidence matrices corresponding to the observations for systematic effects, random additive genetic effects and permanent environmental effects, respectively. The following assumptions were defined for this model:

$$
\begin{array}{r}
\mathrm{y} \mid \mathrm{b}, \mathrm{a}, \mathrm{p}, \mathrm{R} \sim \mathrm{MVN}(\mathrm{Xb}+\mathrm{Za}+\mathrm{Wp}, \mathrm{R}), \\
\operatorname{Var}\left[\begin{array}{c}
a \\
p \\
e
\end{array}\right]=\left[\begin{array}{ccc}
\Lambda_{A} \otimes A & 0 & 0 \\
0 & \Lambda_{P} \otimes I & 0 \\
0 & 0 & R
\end{array}\right]
\end{array}
$$

where $\Lambda_{A}$ and $\Lambda_{P}$ are additive genetic and permanent environmental covariances, respectively, between the regression coefficients for the two traits. $R$ is the residual covariance matrix between the traits. The same residual variance was assumed within intervals and heterogeneous variances between the intervals. $A$ is the numerator relationship matrix between the animals, $I$ is an identity matrix, and $\otimes$ is the direct product operator between the matrices. The following prior distributions were assumed for the model:

$\mathrm{b} \propto$ constant,

$$
\begin{aligned}
& \mathrm{a} \mid \Lambda_{\mathrm{A}} \sim \operatorname{MVN}\left(0, \Lambda_{\mathrm{A}} \otimes \mathrm{A}\right), \\
& p \mid \Lambda_{P} \sim \operatorname{MVN}\left(0, \Lambda_{P} \otimes I\right), \\
& \Lambda_{A} \mid v_{a}, S_{a} \sim I W\left(v_{a}, v_{a} S_{a}\right), \\
& \Lambda_{P} \mid v_{p}, S_{p} \sim \operatorname{IW}\left(v_{p}, v_{p} S_{p}\right), \\
& R \mid v_{e}, S_{e} \sim I W\left(v_{e}, v_{e} S_{e}\right),
\end{aligned}
$$

where, $M N V$ and $I W$ indicate multivariate normal and inverse Wishart distributions, respectively, and $v_{a}, S_{a}, v_{p}, S_{p}, v_{e}$ and $S_{e}$ correspond to the degree of confidence and prior values for additive genetic, permanent environmental and residual covariance matrices, respectively.

The (co)variance components were estimated by Bayesian inference using the Gibbs sampler of the GIBBS3F90 program (Misztal, 2009). A chain length of 1,500,000 cycles was established, with a burn-in period of 150,000 cycles and a sampling interval of 50 cycles, corresponding to 27,000 samples for subsequent analysis. The variance and heritability estimates for each test day and correlations between test days were obtained based on the covariance functions estimated in each cycle. Convergence was tested using the criteria proposed by Heidelberger and Welch (1983) and Geweke (1992). The R software, with some routines of the Bayesian Output Analysis (BOA) package, was used to calculate Geweke's, and Heidelberger and Welch's statistics (Smith, 2007).

\section{RESULTS AND DISCUSSION}

For the two lactations, average TDMY increased until the second test day, i.e., peak 
lactation, and decreased, thereafter (Table 2). The occurrence of peak production on, as early as the second test day is common in Gyr cattle. Consequently, the period of lactation is short and lactation persistency is lower when compared to European breeds.

Table 2. Number of observations (N), average milk yield (MY), standard deviation (SD), and number of observations per contemporary group (CG) for monthly test-day milk yields (TDMY) of two lactations in Gyr cows.

\begin{tabular}{|c|c|c|c|c|c|c|c|c|}
\hline & \multicolumn{5}{|c|}{ Lactation 1} & \multicolumn{3}{|c|}{ Lactation 2} \\
\hline & $\mathrm{N}$ & MY (kg) & $\mathrm{SD}(\mathrm{kg})$ & CG & $\mathrm{N}$ & MY (kg) & $\mathrm{SD}(\mathrm{kg})$ & CG \\
\hline 1 & 4041 & 11.3 & 4.6 & 1.107 & 1.251 & 11.0 & 5.5 & 403 \\
\hline 2 & 4826 & 12.6 & 5.5 & 1.173 & 1.393 & 14.1 & 5.9 & 437 \\
\hline 3 & 4870 & 12.3 & 5.8 & 1.235 & 1.416 & 13.3 & 5.9 & 443 \\
\hline 4 & 4795 & 11.9 & 5.7 & 1.219 & 1.369 & 12.4 & 5.7 & 443 \\
\hline 5 & 4471 & 11.5 & 5.7 & 1.174 & 1.318 & 11.6 & 5.2 & 432 \\
\hline 6 & 4228 & 10.9 & 5.6 & 1.135 & 1.266 & 10.8 & 5.0 & 427 \\
\hline 7 & 3992 & 10.4 & 5.4 & 1.096 & 1.208 & 10.0 & 4.8 & 417 \\
\hline 8 & 3748 & 9.8 & 5.2 & 1.024 & 1.082 & 9.2 & 4.6 & 398 \\
\hline 9 & 3374 & 9.2 & 5.0 & 995 & 939 & 8.6 & 4.4 & 370 \\
\hline 10 & 2993 & 8.9 & 4.8 & 908 & 748 & 8.0 & 4.1 & 326 \\
\hline
\end{tabular}

The estimates of phenotypic variances for TDMY indicated similar trajectories for the two lactations, which however, differed in magnitude (Figure 1). Different tendencies of phenotypic variances for first lactation have been reported in the studies of DeGroot et al. (2007) and Biassus et al. (2011), with higher estimates at the beginning and end of lactation. In general, the phenotypic variance estimates for TDMY in this study were higher in the second lactation, a finding also observed in other studies (Jamrozik et al., 1997; Strabel and Jamrozik, 2006).

A

Lactation 1

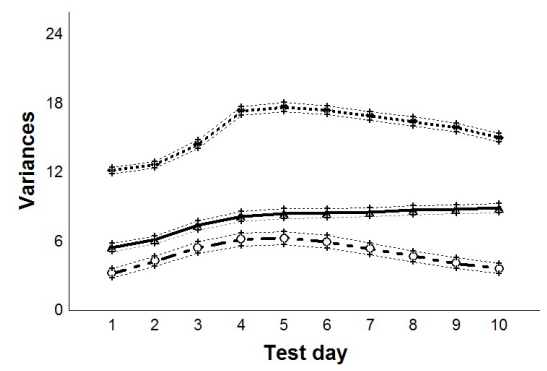

+- $95 \%$ confidence intervals

B

Lactation 2

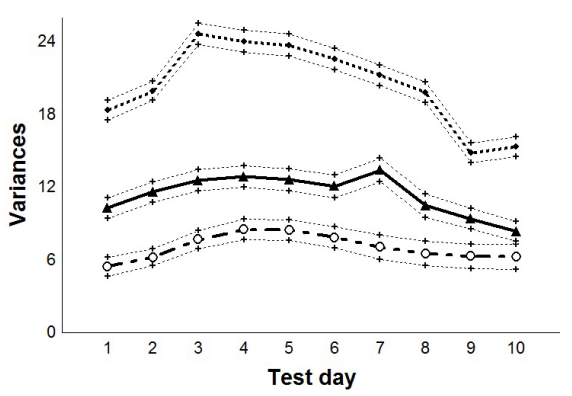

additive genetic

permanent environmental

phenotypic

Figure 1. Posterior means and respective $95 \%$ confidence intervals for additive genetic, permanent environmental, and phenotypic variances of test-day milk yields in the first (A) and second lactation (B) of Gyr cows, obtained with bivariate random regression models using Bayesian inference. 
The additive genetic variances (Figure 1) increased until TDMY4 and 5, and decreased thereafter until the end of lactation, in the two lactations. These results differ from those reported by Biassus et al. (2011), who found an increase in variances across lactation. A decrease in additive variance at the end of lactation has been observed in other studies (Pool et al., 2000; Lopez-Romero et al., 2003; Costa et al., 2008). This reduction has been attributed to the smaller number of observations during this stage of lactation, a fact that leads to difficulties in adjusting the mathematical functions used for the description of additive and permanent environmental effects. In contrast, DeGroot et al. (2007) observed an increase in additive variances from midlactation to the end of lactation in the first three lactations of Holstein cows. The magnitude of the additive variance estimates was higher for TDMY of the second lactation when compared to the first lactation, in agreement with other studies (Strabel and Jamrozik, 2006; DeGroot et al., 2007). However, the differences were of low magnitude.

The permanent environmental variance estimates showed different tendencies in the two lactations, increasing with days in milk in the first lactation and decreasing after the seventh test day in the second lactation. Higher estimates were obtained for most TDMY in the second lactation (Figure 1). Similar results have been reported in different studies (Fujii and Susuki, 2006; Araujo et al., 2006; Cobuci et al., 2011).

The magnitudes of the posterior mean heritabilities showed different tendencies in the two lactations, especially for the first TDMY and the two test days at the end of lactation (Table 3). In the first lactation, the heritabilities increased from early lactation $(0.26)$ until TDMY3 (0.38), followed by a decrease until the end of lactation. In the second lactation, the estimates increased from the first $(0.29)$ to the fifth test day $(0.36)$, with a slight decrease thereafter, and again increased on the last two test days (0.34 and 0.41). In general, the tendency of the heritabilities for TDMY in the first and second lactations was similar to that observed by Bormann et al. (2005), De Roos et al. (2004), and Cobuci et al. (2011), i.e., lower heritabilities at the beginning of lactation, an increase until mid-lactation, and a subsequent decrease until the end of lactation. However, lower estimates were reported in the cited studies, in addition to the observation of higher heritabilities for first-lactation TDMY. For Gyr cattle, Pereira et al. (2013), using first-lactation milk yield records, reported magnitudes of heritabilities similar to that found in the present study for first-lactation yields, with higher estimates in the first-third of lactation and a tendency toward a reduction with advancing lactation.

Table 3. Means and $95 \%$ credibility intervals $(95 \mathrm{Cl})$ of heritability estimates for test-day milk yield (TDMY) in the first two lactations of Gyr cows obtained with bivariate random regression models using Bayesian inference.

\begin{tabular}{|c|c|c|c|c|}
\hline & \multicolumn{2}{|c|}{ Lactation 1} & \multicolumn{2}{|c|}{ Lactation 2} \\
\hline & Mean & $95 \mathrm{Cl}$ & Mean & $95 \mathrm{Cl}$ \\
\hline 1 & 0.26 & $0.18-0.35$ & 0.29 & $0.19-0.43$ \\
\hline 2 & 0.34 & $0.24-0.44$ & 0.31 & $0.23-0.40$ \\
\hline 3 & 0.38 & $0.29-0.47$ & 0.31 & $0.23-0.39$ \\
\hline 4 & 0.35 & $0.27-0.45$ & 0.35 & $0.28-0.45$ \\
\hline 5 & 0.35 & $0.28-0.44$ & 0.36 & $0.26-0.44$ \\
\hline 6 & 0.34 & $0.26-0.42$ & 0.35 & $0.25-0.44$ \\
\hline 7 & 0.32 & $0.24-0.40$ & 0.33 & $0.23-0.44$ \\
\hline 8 & 0.28 & $0.20-0.39$ & 0.33 & $0.23-0.45$ \\
\hline 9 & 0.26 & $0.18-0.34$ & 0.34 & $0.20-0.49$ \\
\hline 10 & 0.24 & $0.16-0.31$ & 0.41 & $0.27-0.57$ \\
\hline
\end{tabular}

The genetic correlations of milk yields between two test days within lactation ranged from 0.35 to 0.99 (Figure 2). In general, the genetic correlations were higher between adjacent test days, 
and they decreased with increasing distance between test days, in agreement with the results of other studies (Liu et al., 2001; Cobuci et al., 2011). The lowest estimates within the same lactation occurred between the 1 st and 10 th test day and were 0.46 and 0.48 for the first and second calving, respectively. The highest estimate was observed between the $4^{\text {th }}$ and $5^{\text {th }}$ test day ( 0.99 for each lactation).

Although the variation in genetic correlations was similar in the two lactations, the magnitude of these correlations tended to decrease with increasing calving order. Furthermore, there was a greater variation in the genetic correlations between second lactation TDMY when compared to the estimates of the first lactation (Figure 2).

A

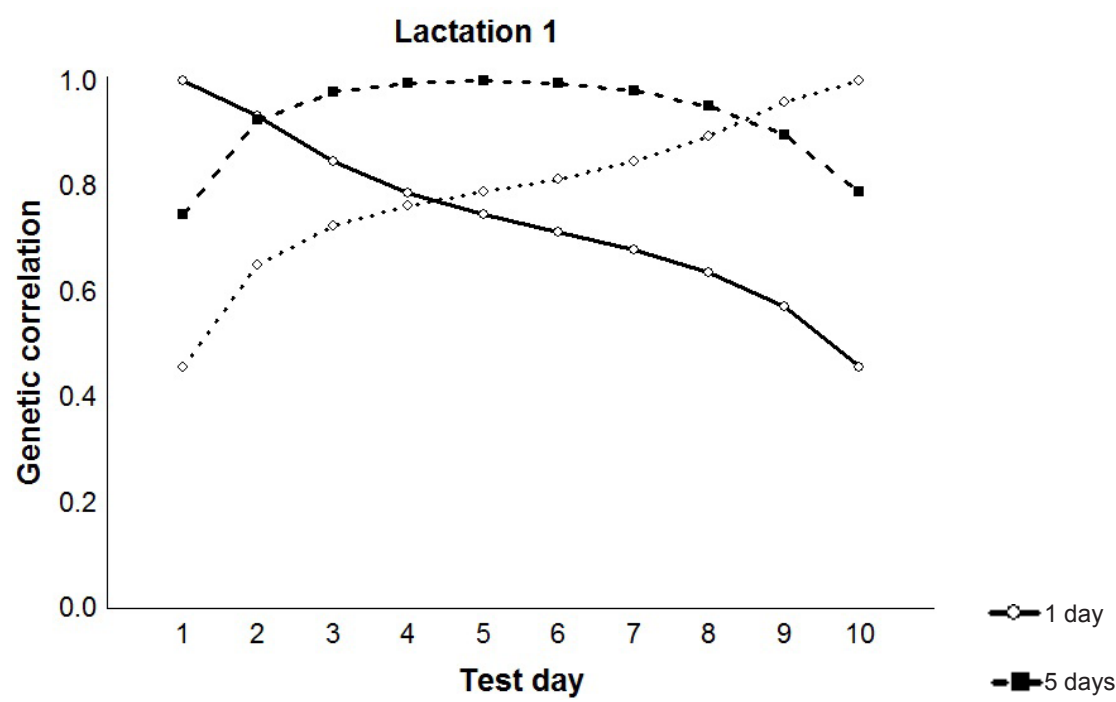

B

Lactation 2

$\bullet \bullet \cdot 10$ days

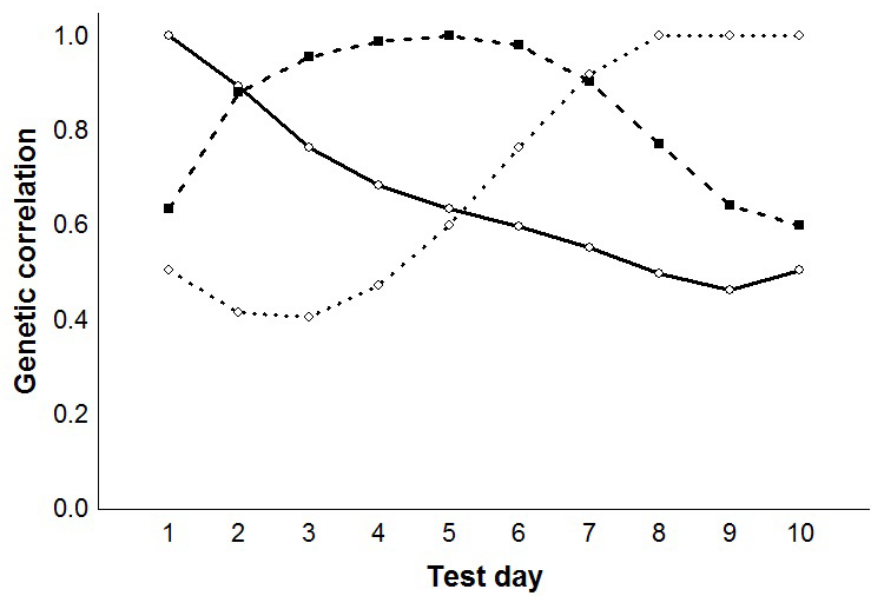

Figure 2. Estimates of genetic correlation between milk yields on test days 1,5 and 10 and the remaining test days for the first (A) and second (B) lactation of dairy Gyr cows, obtained with bivariate random regression models. 
The permanent environmental correlations between test days ranged from 0.42 to 0.99 in each lactation (Figure 3). The lowest estimates were obtained between the 1st and 10th test day in the first and second lactation, and the highest estimates between the 7th and 8th test day in the first lactation and between the 2nd and 3rd test day in the second lactation. The permanent environmental correlations were higher between milk yields of adjacent test days and decreased with increasing distance between test days (Liu et al., 2001; Bignardi et al., 2009; Cobuci et al., 2011).

A

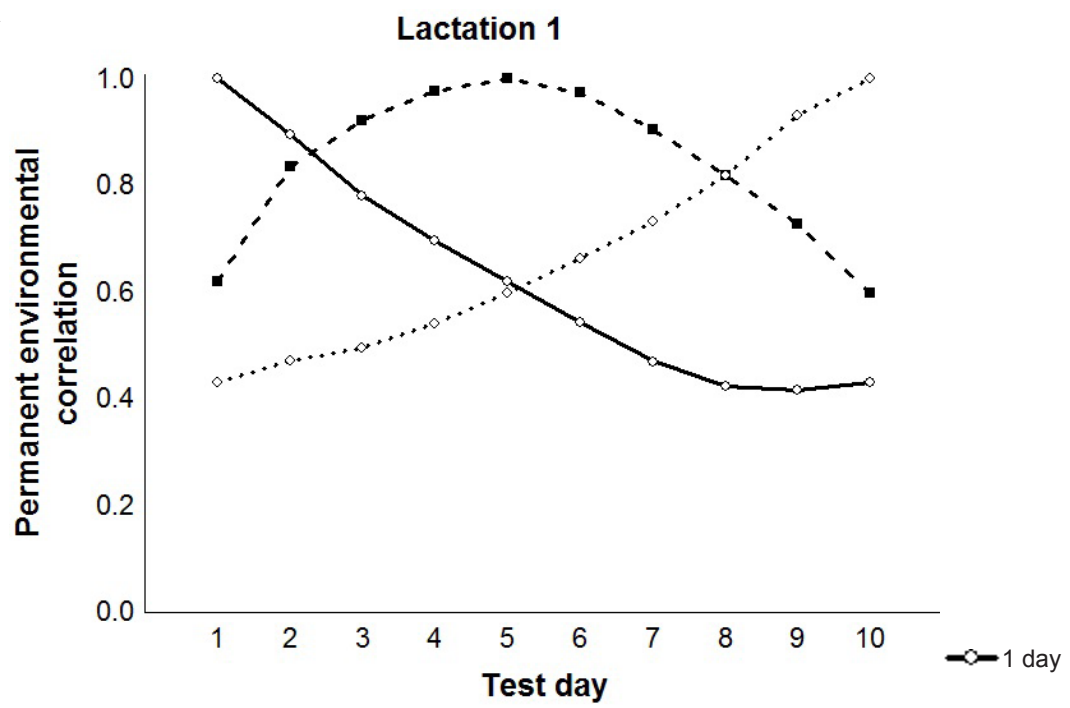

B

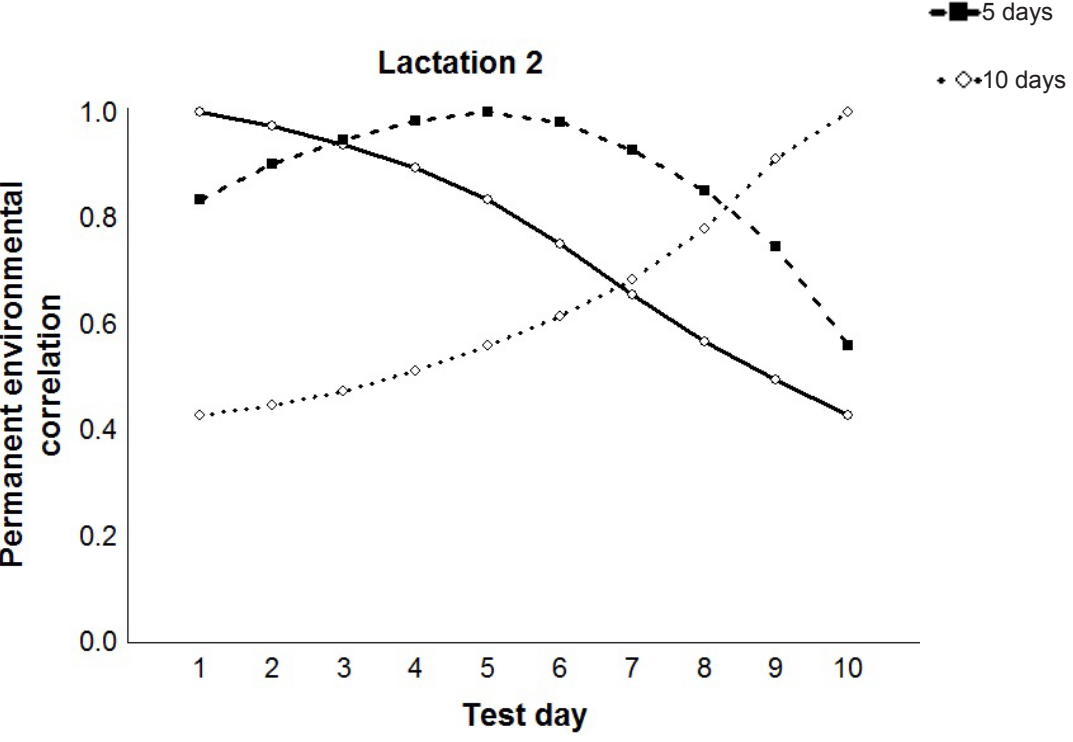

Figure 3. Estimates of permanent environmental correlation between milk yields on test days 1, 5 and 10 and the remaining test days for the first $(\mathbf{A})$ and second $(\mathbf{B})$ lactation of Dairy Gyr cows, obtained with bivariate random regression models. 
Figure 4 shows the genetic and permanent environmental correlations, respectively, between milk yields on the 1st, 5th, and 10th test day of the first lactation and TDMY of the second lactation. In general, the genetic correlations showed the same trend as the permanent environmental correlations. However, higher magnitudes were observed for the genetic correlations, ranging from 0.38 to 1.00 , whereas the permanent environmental correlations ranged from 0.09 to 0.99 .

A

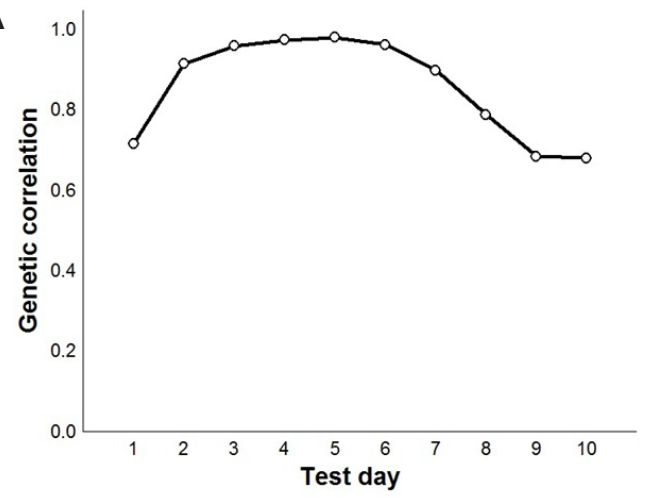

C

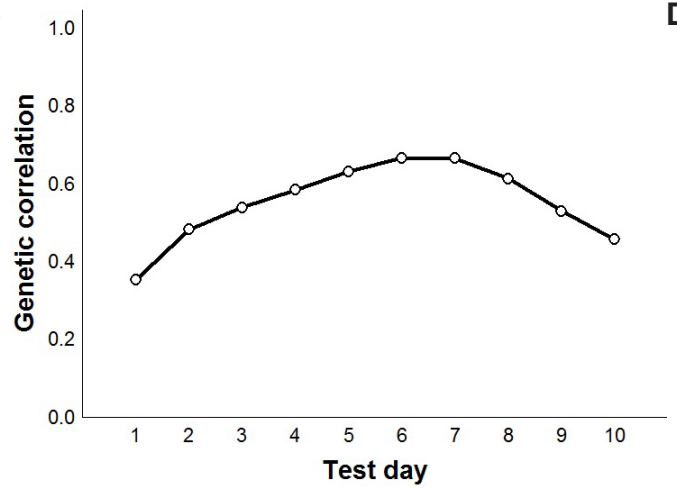

E

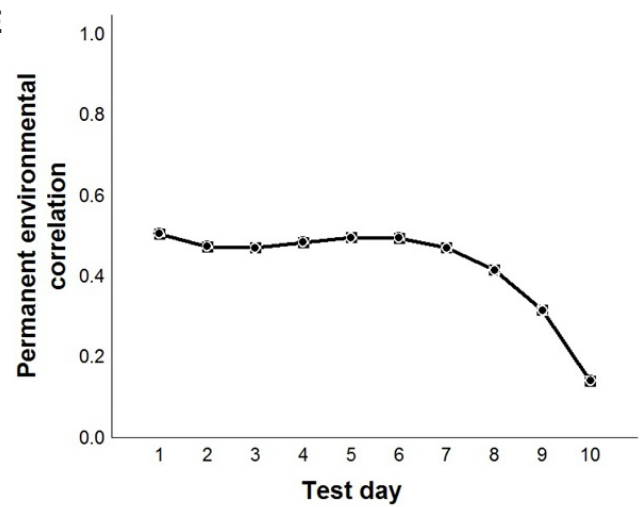

B

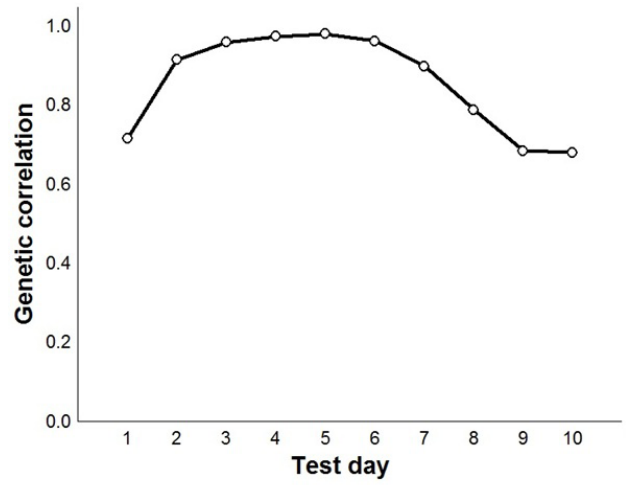

D

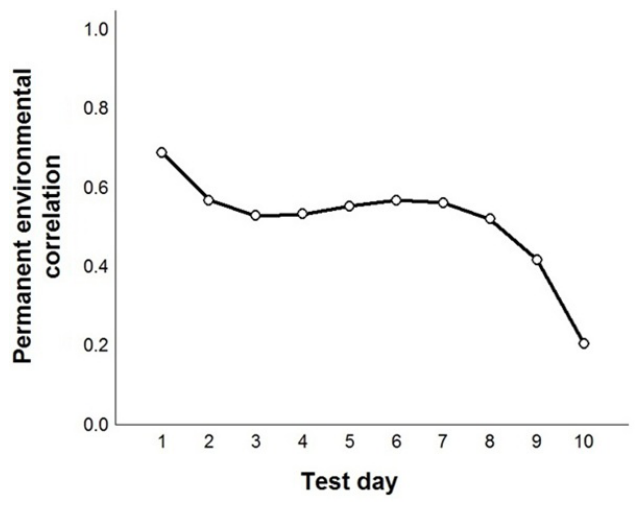

$\mathbf{F}$

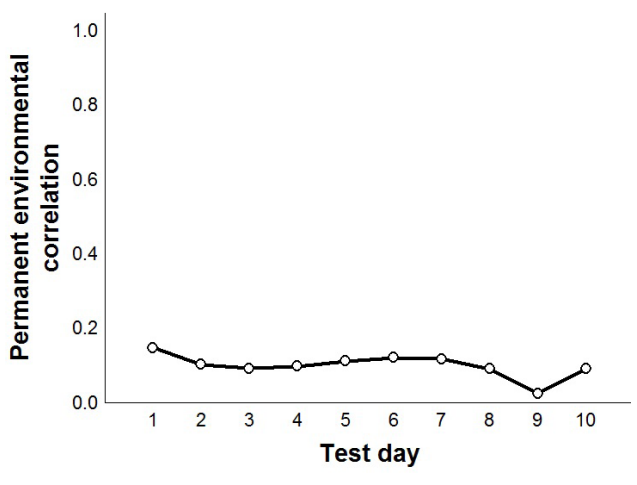

Figure 4. Estimates of genetic $(A, B, C)$ and permanent environmental $(D, E, F)$ correlations between first-lactation milk yields on test days 1st ( $\mathbf{A}$ and $\mathbf{D})$, 5th ( $\mathbf{B}$ and $\mathbf{E})$ and 10th (C and $\mathbf{F}$ ) and all test-day milk yields of the second lactation of dairy Gyr cows, obtained with bivariate random regression models. 
High genetic and permanent environmental correlations were observed between firstlactation TDMY and equivalent and adjacent TDMY of the second lactation, except for 10th TDMY. In general, the results are in agreement with the results reported by Guo et al. (2002), Yang et al. (2005), and Strabel and Jamrozik (2006). The correlations of first-lactation TDMY with those of the second lactation decreased with increasing distance between equivalent test days, except between the 10th TDMY of first lactation and all TDMY of second lactation (Figure 4C), whose genetic correlation estimates were smaller than 0.70 .

The positive and medium to high genetic correlations between first-lactation TDMY and the remaining TDMY of the second lactation indicate the existence of a group of genes that affects them in a desirable direction. However, the last part of first and second lactation showed lower genetic correlation with the previous parts and could cause some changes in ranking of sires if only first lactation information would be used. An explanation of this occurrence could be that the breeders record first lactation milk production of cows only if their production is higher than the overall mean of herds.

The analysis of milk yield using bivariate RRM permits to combine the information of correlated traits, in this case, TDMY of different lactations, to predict the genetic merit of animals for traits such as 305-day cumulative milk yield and lactation persistency. Therefore, an RRM including two lactations would consider a larger number of records per cow, which will contribute to more accurate predictions of genetic parameters and breeding values.

\section{CONCLUSIONS}

Heritability estimates for the first and second lactation presented moderate values. The genetic correlation estimates ranged from moderate to high, demonstrating genetic association between milk yields across lactation in the same direction, but suggesting differences in this association between periods of lactation. Therefore, the genetic parameters in the first and second lactation obtained in this study indicated the possibility of using test-day records for the prediction of breeding values for milk yield in this population of the Gyr breed.

\section{Conflicts of interest}

The authors declare no conflict of interest.

\section{ACKNOWLEDGMENTS}

The authors are grateful to Associação Brasileira dos Criadores de Zebu (ABCZ), for providing the data set.

\section{REFERENCES}

Araújo CV, Torres RA, Costa CN, Torres Filho RA, et al. (2006). Random regressions models to describe the genetic variation of milk yield in Holstein breed. Braz. J. Anim. Sci. 35: 975-981.

Biassus IO, Cobuci JA, Costa CN, Rorato PRN, et al. (2011). Genetic parameters for production traits in primiparous Holstein cows estimated by random regression models. Rev. Bras. Zootec. 40: 85-94.

Bignardi AB, El Faro L, Albuquerque LG, Cardoso VL, et al. (2009). Random regression models to estimate test-day milk yield genetic parameters Holstein cows in southeastern Brazil. Livest. Sci. 123: 1-7. 
Bormann J, Wiggans GR, Druet T and Gengler N (2005). Within-herd effects of age at test day and lactation stage on test-day yields. J. Dairy Sci. 86: 3765-3774.

Bozdogan H (2000). Akaike's information criterion and recent developments in information complexity. J. Math Psychol. 44: 62-91.

Cobuci JA, Euclydes RF, Lopes PS, Costa CN, et al. (2005). Estimation of genetic parameters for test-day milk in Holstein cows using a random regression model. Genet. Mol. Biol. 28: 75-83.

Cobuci JA, Costa CN, Neto JB and Freitas AF (2011). Genetic parameters for milk production by using random regression models with different alternatives of fixed regression modeling. Rev. Bras. Zootec. 40: 557-567.

Costa CN, Melo CNR, Pacher IU, Freitas AF, et al. (2008). Genetic parameters for test-day milk yield of first lactation Holstein cows estimated by random regression using Legendre polynomials. Rev. Bras. Zootec. 37: 602-608.

DeGroot BJ, Keown JF, Van Vleck LD and Kachman SD (2007). Estimates of genetic parameters for Holstein cows for test-day yield traits with a random regression cubic spline model. Genet. Mol. Res. 6: 434-444.

De Roos AP, Harbers AG and de Jong G (2004). Random herd curves in a test-day model for milk, fat, and protein production of dairy cattle in the Netherlands. J. Dairy Sci. 87: 2693-2701.

El Faro L and Albuquerque LG (2003). Utilização de modelos de regressão aleatória para produção de leite no dia do controle, com diferentes estruturas de variâncias residuais. Rev. Bras. Zootec. 32: 1104-1113.

Fuji C and Suzuki M (2006). Comparison of homogeneity and heterogeneity of residual variance using random regression testday models for first lactation japanese Holstein cows. Anim. Sci. J. 77: 28-32.

Geweke J (1992). Evaluating the accuracy of sampling-based approaches to the calculation of posterior moments. In: Bayesian Statistics (Bernardo JM, Berger JO, Dawid AP and Smith AFM, eds.). Clarendon Press, 169-193.

Guo Z, Lund MS, Madsen P, Korsgaard I, et al. (2002). Genetic parameter estimation for milk yield over multiple parities and various lengths of lactation in Danish Jerseys by Random Regression Models. J. Dairy Sci. 85: 1596-1606.

Heidelberger P and Welch P (1983). Simulation run length control in the presence of an initial transient. Oper. Res. 31: 11091144.

Jamrozik J and Schaeffer LR (1997). Estimates of genetic parameters for a test day model with random regressions for yield traits of first lactation Holsteins. J. Dairy Sci. 80: 762-770.

Jamrozik J, Schaeffer LR, Liu Z and Jansen G (1997). Multiple trait random regression test day model for production traits. Interbull Bulletin 16: 43-47.

Kirkpatrick M, Hill WG and Thompson R (1994). Estimating the covariance structure of traits during growth and ageing, illustrated with lactation in dairy cattle. Genet. Res. 64: 57-69.

Liu Z, Reinhardt F, Bünger A, Droop L, et al. (2001). Application of a random regression model to genetic evaluations of test day yields and somatic cell scores in dairy cattle. Interbull Bull. 27: 159-166.

López-Romero P, Rekaya R and Carabaño MJ (2003). Comparing alternative random regression models to analyze first lactation daily milk yield data in Holstein-Friesian cattle. Livest. Prod. Sci. 82: 81-96.Meyer K (1999). Estimates of genetic and phenotypic covariance functions for postweaning growth and mature weight of beef cow. J. Anim. Breed. Genet.116: 181-205.

Meyer K (2006). "Wombat" - digging deep for quantitative genetic analyses using restricted maximum likelihood. Proceedings of the 8th World Congress of Genetic and Applied Livestock Production, Belo Horizonte, 13-18.

Misztal I (2009). BLUPF90: a flexible mixed model program in Fortran 90. Livest. Sci. 124: 156-162.

Pereira RJ, Bignardi AB, El Faro L, Verneque RS, et al. (2013). Random regression models using legendre polynomials or linear splines for test-day milk yield of dairy Gyr (Bos indicus) cattle. J. Dairy Sci. 96: 565-574.

Pool MH, Janss LL and Meuwissen TH (2000). Genetic parameters of legendre polynomials for first parity lactation curves. J. Dairy Sci. 83: 2640-2649.

Reis Filho JC (2006). Endogamia na raça Gir. Master's thesis, UFV, Viçosa.

Schaeffer LR (2008). Random regression. Available at [http://www.aps.uoguelph.ca/\%7Elrs/ABModels/NOTES/RRM14a.pdf]. Accessed July 15, 2014.

Smith BJ (2007). Boa: An R package for MCMC output convergence assessment and posterior inference. J. Stat. Softw. 21: 1-37.

Strabel T, and Jamrozik J (2006) Genetic analysis of milk production traits of Polish black and white cattle using large-scale random regression test-day models. J. Dairy Sci. 89: 3152-3163.

Tier B and Meyer K (2004). Approximating prediction error covariances among additive genetic effects within animals in multiple-trait and random regression models. J. Anim. Breed. Genet. 121: 77-89.

Wolfinger R (1993). Covariance structure selection in general mixed models. Commun. Stat. Simul. C 22: 1079-1106.

Yang RQ, Ren HY, Schaeffer LR and Xu SZ (2005). Estimation of genetic parameters for lactational milk yields using twodimensional random regressions on parities and days in milk in Chinese Simmental cattle. J. Anim. Breed. Genet. 122: 49-55. 